\title{
A correlation analysis of the spot market prices of the Romanian electricity sector
}

\author{
Mihail BUSU \\ The Bucharest University of Economic Studies, Bucharest, Romania \\ mihail.busu@fabiz.ase.ro \\ Roxana CLODNIȚCHI \\ The Bucharest University of Economic Studies, Bucharest, Romania \\ Manuela Liliana MUREȘAN \\ The Bucharest University of Economic Studies, Bucharest, Romania
}

\begin{abstract}
The energy sector is particularly important in the national economy as a whole, while the electricity sector is its main component. The developments in this area have strong economic and social repercussions. This article makes an overview of the electricity sector, illustrating the monthly evolution of consumption and production of instantaneous electricity in Romania in the past few years. Further on, the paper presents the monthly evolution of instantaneous consumption and production of electricity in Romania, the annual structure of electricity production and the depiction of some basic indicators of centralized electricity markets managed by OPCOM. The quantitative analysis presents the monthly evolution of weighted average prices on the competitive markets managed by OPCOM and a linear correlation analysis of the spot market prices in the Eastern European region. The conclusions of the article are in line with the research in the field and show that the electricity markets have registered important evolutions in Romania, both in terms of size and prices, evolutions based on both structural and behavioral factors. It also showed that spot market prices had relatively similar developments over the period analyzed in several countries in the region, with price correlations that seem to be even stronger as the interconnection of electricity grids is higher. Therefore, the results confirm the economic theory, namely that increasing the interconnection of electricity markets can lead to energy prices being brought closer, but also to mitigating the shocks affecting these markets.
\end{abstract}

Keywords: electricity sector, spot market prices, correlation analysis, production structure, OPCOM

Please cite the article as follows: Bușu, M., Clodnițchi, R. and Mureșan M.L. (2019), "A correlation analysis of the spot market prices of the Romanian Electricity Sector", Management \& Marketing. Challenges for the Knowledge Society, Vol. 14, No. 1, pp. 150-162, DOI: 10.2478/mmcks-2019-0010.

\section{Introduction}

The energy sector, and in particular the production and distribution of electricity, represents a key sector in the national economy. Also, Romania is participating in an ample process of integrating energy markets at EU level, resulting in more open competition on energy markets. For this reasons, Romanian authorities have scrutinized the electricity market using the full range of instruments: investigating anticompetitive practices, merger control, advocacy for adequate legislative measures and continuous monitoring of developments in the electricity markets.

Simultaneously, the multiple technological developments, doubled by green policies translated in E-RES support schemes, have led to an increase in the energy production in recent years. On European markets, influenced by energy efficiency policies, there has been 
a slight decrease in energy demand but also a diversification of supply. The spectacular decrease in the cost of energy production from RES, the promise of commercial electricity storage in the coming years, the emergence of electromobility, the progress of energy management systems and digitization represent important challenges to the conventional energy production, transport and consumption paradigm.

On top of this, the EC presented 2016 its second reform package "Clean Energy for All", which implies the updating of the directive and regulation on the rules for the functioning of the market, the Regulation on the European Agency for the Cooperation of Energy Regulators (ACER) as well as the regulation on risk management in the electricity sector. At the end of 2018 the new directive was published, which aims at "developing transmission and distribution grid infrastructure, intelligent networks, storage facilities and interconnections, with the objective of arriving at a $15 \%$ electricity interconnection target by 2030, in order to increase the technically feasible and economically affordable level of renewable energy in the electricity system" (EP \& C, 2018).

The new, improved single electricity market model stands for the removal of price caps, the harmonization of dispatch rules for all types of capacities (incl. intermittent RES), the reduction of congestion situations of the cross-border interconnection infrastructure of the electricity grids, better coordination between transmission system operators and investments in balancing capacities, better remuneration for the participation of electricity consumers in the balancing market through demand-side management. Additionally ENTSO$E$ has been launched as a distribution network operator coordinating entity, with attributions in the integration of RES, distributed generation of electricity, electricity storage, smart meters, control systems, etc. (ENTSO-E, 2019).

2018 Romania has an interconnection capacity of 7\%, and by 2020 it is expected to grow up to $9 \%$. The target of $10 \%$ will not be reached, decision makers are however optimistic about reaching the 15\% interconnection target for 2030. Apart from interconnections with Hungary, Bulgaria and Serbia, the Romanian Energy Strategy - Draft (Romanian Ministry for Energy, 2018) foresees the need to develop interconnections with neighboring countries outside the EU (Moldova, Ukraine). The interconnection of Romania's electricity transmission system with the System of Republic of Moldova represent a strategic objective of the governments of both countries.

Considering all the above, and the still existing disparities in income levels within the EU and in its neighboring countries, our study tests if the grade of interconnectivity between national grids is correlated with the evolution of electrical energy prices in the connected countries. In order to reach our research objective, we analyse the monthly evolution of weighted average prices on the competitive markets as well as the spot market prices in several countries in the SEE region.

This paper starts with a literature review, continues with an comprehensive overview of the Romanian electricity sector in the past three years, illustrating the monthly evolution of consumption and production of instantaneous electricity in Romania. Subsequently we will present the annual structure of electricity production and the depiction of some basic industry indicators. A quantitative analysis is further presented based on data from the competitive markets managed by OPCOM and other SEE Market Operators. The article concludes with a discussion and conclusions section. 


\section{Literature review}

Until 1995 Hungary, Slovakia, the Czech Republic, Poland, Romania and Bulgaria were not part of the UCTE grid. The Serbian, Montenegrin, Bosnian, FYR Macedonian, Albanian, Greek, Romanian and Bulgarian power systems were isolated and operated as a second synchronous UCTE zone. Less than 15 years ago, in the autumn of 2004, the South East European (SEE) power system has been connected in unified parallel operations followed by dramatical changes in the power system conditions in SEE. This time coincides with the entering of power utilities from this region in deregulation and privatization process. The post-socialistic collapse of industrial consumption leads to a surplus of installed power generation capacities. From this point onward, cheaper electricity from SEE becomes a great market opportunity and the energy market in SEE region starts developing. Majestrovic et al. (2006) present 2006 a first overview of the electricity market in the SEE region, discuss advantages and disadvantages of regional markets and analyse theirs influence on the regional security of supply.

Zachmann (2008) is one of the first authors testing the hypothesis that the restructuring process taking place in the European electricity sector leads to a common European market for electricity. He performs a Principal Component Analysis (PCA) of wholesale electricity prices in 2002-2006. Within his paper he rejects the assumption of full market integration but identifies pairs of countries, for which (bilateral) convergence can be proved. In the same year, Majstrovic et al. (2008) publishes an analysis based on correlation and regression of wholesale electricity prices in 13 European countries, which showes strong market correlation within two European market zones: Scandinavian and Continental Europe (Germany, Holland France, Austria and Spain). At this moment the other two analysed markets (Italian and Polish) are poorly correlated to all other markets.

Kennedy's 2005 published article regarding Romania's possible entrance in the SEE Regonal Energy Market, is probably one of the first articles centered on Romania's role in in regional energy market and takes the Athens Memorandum(AM) as its starting point. The AM constitutes the basis for the development of a South-Easter European regional energy market in power and gas (SEEREM). This regional market shall be liberalised in a phased manner from 2005, and become ultimately a part of the EU's internal energy market. He analyses the extent to which Romania, who is traditionally a net energy exporter, complies with requirements under the AM, and the challenges derived from a successful SEEREM accession. The paper presents an overview of Romania's energy sector 2005 with its strengths and challenges. Kennedy sees further power price increases as a requirement in the medium term, just like the improvement of the payments discipline.

Karova presents in her 2011 published paper an overview on the eight European regional electricity market (REM) covering the South East European countries. She argues that the SEE REM deals with the same priority issues as the other REMs do, and that the progress of this REM is great despite the short time of its existence.

Cristea (2013) looks into the degree of "openness" of the electricity market, and the manner in which EU directives regarding the electricity market liberalization, the transactions and the auction based framework are enforced. Moraru and Hristescu (2016) explore price mechanisms in order to compensate the oversupply on OPCOM Romanian centralized day-ahead platform - during windy days or summer peak hours - caused by the changes in the primary and secondary legislation on the wholesale power market. The 
Marginal Price mechanism on day-ahead market decreases prices in those hours, below baseload generators variable cost, leading to commercial losses for renevable energy producers, or even more than this, to the inability to secure long term investments in baseload generation capacity to replenish the existing ones. The paper concludes that a different new mechanism needs to be developed or an adjustment to the existing one needs to be achieved in order to secure economic efficiency in the Romanian power generation system.

Analyses of spot market prices of the Romanian electricity sector have been performed by many researchers. The country's energy production has been raised in the past years (Bianco et. al., 2014). The electricity industry is a large and high-growth sector of the Romanian economy (Mala and Timilsina, 2019). Nevertheless, this growth consisting mainly in e-RES capacity, does not explain the price evolution on the electricity markets. Paun D. and C.A. (2017) assess the impact of RES on energy market prices and base their study on monthly data from 2008 to 2014. Using the Least Squares methodology and multiple regression analysis they analyse the impact of each source (coal, nuclear, gas, hydro etc.) on the price evolution and show that the introduction of renewable energy sources, has not led to an increase in the price of energy.

In fact, Romania is an electricity exporter to its neighbors (Cirstea et. al., 2018). The future role of the country on the Balkan electricity market will depend on the new investments in electricity generation and transmission capacity planned for subsequent years, in order to substitute obsolete plants and to strengthen the position as an electricity producer and exporter country (Marić and Vukmirović, 2018).

Romania has committed itself to an electricity restructuring plan that includes vertical separation, but plans remain uncertain regarding the horizontal restructuring of generation (Diaconu et. al., 2009). Among the more important issues yet to be decided are how hydro capacity will be allocated and how many thermal generation enterprises will be created, and with what assets (Bianco et. al., 2010; Verbic et. al., 2017).

\section{An overview of the Romanian Electricity Sector}

The analysis of the energy sector begins with an overview of the electric energy sector, respectively with the monthly evolution of consumption and production of instantaneous electric energy in Romania from January 2016 to August 2018.

As noted from the chart below, the electricity production was predominantly higher than consumption, during the analyzed period, sometimes even with high values of the differences between production and consumption, which means that for most of the time Romania played a net exporter role for electricity in the region. During the analyzed period, the approximation of consumption and production of electricity took place only sporadically, apparently during the month of May of each year, and during July-September of the year 2017. Even in these conditions, data published by Transelectrica shows that Romania was a net exporter of electricity in about 80\% of time between January 2016 and August 2018. 


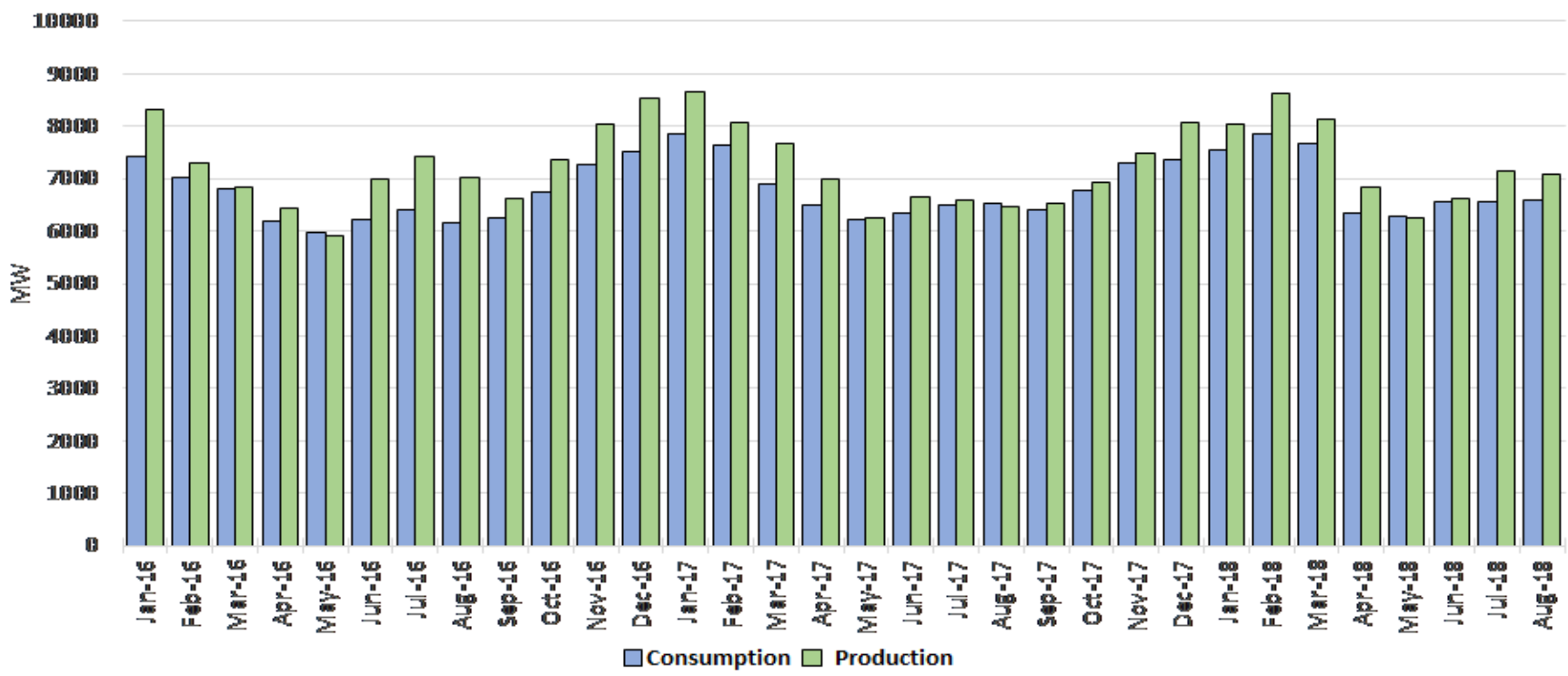

Figure 1. Monthly evolution of average production and consumption of electricity in Romania, during January 2016 - August 2018

Source: own processing of the data published in the annual activity reports of Transelectrica Annual data on electricity production and consumption indicate a $3 \%$ increase in consumption in 2017 compared to the previous year, with a slight decrease in output (-0.6\%). In the first eight months of 2018 , the consumption trend continued $(+1.7 \%$ compared to the same period the previous year), but this time the increase in consumption was supported by the increased production ( $+2.4 \%$ compared to the same time in 2017$)$, especially due to a higher hydraulicity in 2018.

The following graph presents the annual aggregate evolution of the electricity production structure and shows some differences between 2017 and the rest of the analyzed period. Moreover, due to a reduced hydraulicity, 2017 was characterized by a lower production of hydroelectricity, a reduction of about 5.5 percentage points (pp) compared to the previous year, from the cheapest source of electric energy, which was compensated by the increased production of coal $(+2 \mathrm{pp})$, the production of wind $(+1,5 \mathrm{pp})$ and the hydrocarbon $(+1,4 \mathrm{pp})$, and only partially in the rise in the nuclear source $(+0,5 \mathrm{pp})$. It is noteworthy that the technologies that reduced the contribution of the hydro source in 2017 are characterized by higher production costs, which put pressure on the price of electricity. 


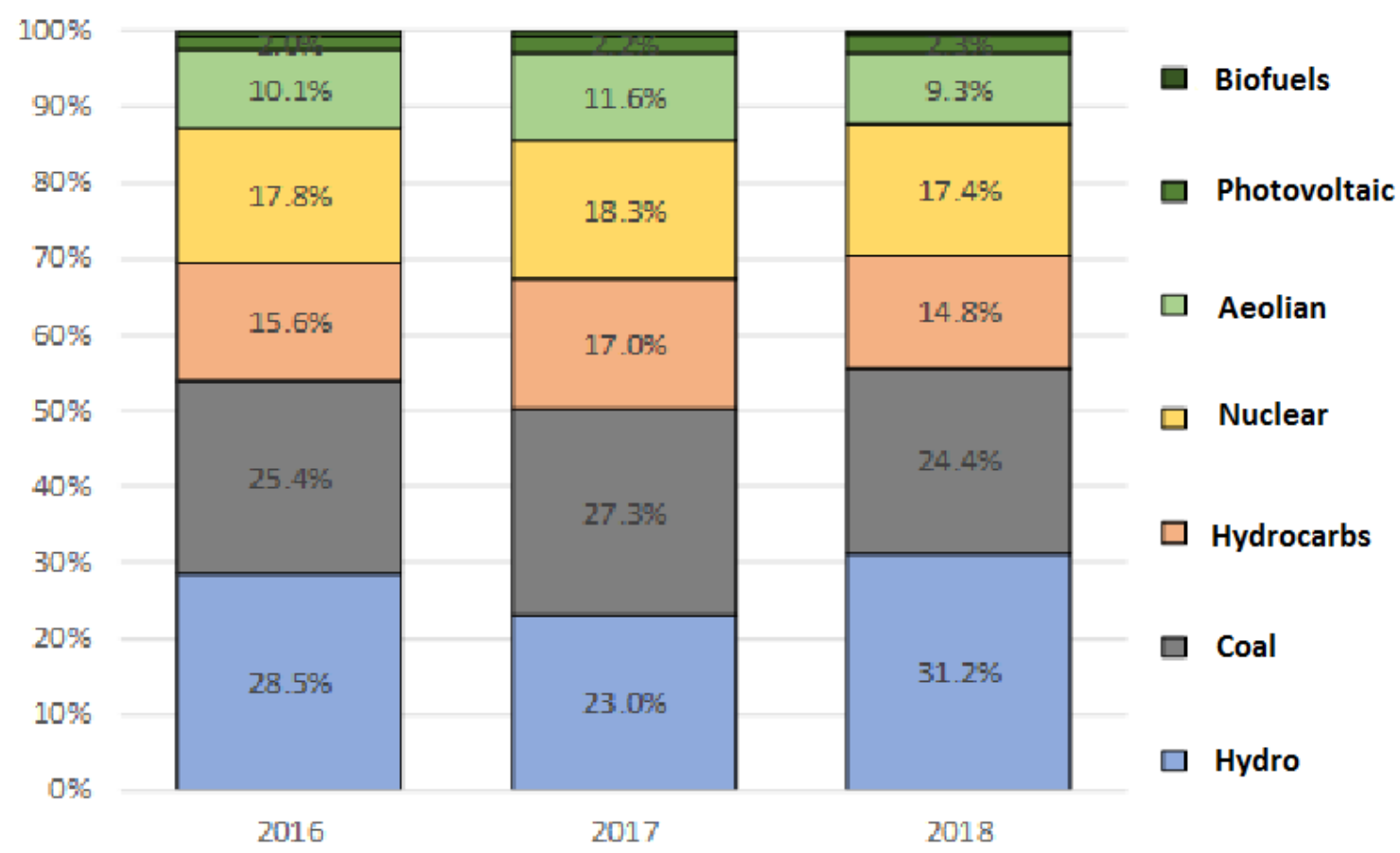

Figure 2. Annual electricity production structure, January 2016 - August 2018

Source: Author's own processing of the data published in the annual activity reports of Transelectrica

The first eight months of 2018 appear to be marked by conditions significantly different from those characterizing the year 2017, respectively by a much more significant contribution of the hydro source to the production of electricity. The difference of over $8 \mathrm{pp}$ of this source in the first eight months of the year and in 2018 was achieved mainly at the expense of four technologies listed above, such as those based on carbon is $(-2,9 \mathrm{pp})$, wind ($2,3 p p)$, hydrocarbons (-2,2pp) and to a lesser extent, of its nuclear technology (-0.9pp).

The graph above shows that the total renewable sources of production decreased from $41.3 \%$ in 2016 to $37.4 \%$ in 2017 to $43.4 \%$ in the first eight months of 2018 . The evolution of the production and consumption of electricity in Romania in the period January 2016 - August 2018, combined with changing production share of each source in total, as well as elements related to the behavior of the market, had a significant impact on prices which are traded on the electricity market.

\section{Results and discussions}

The information provided below represents useful inputs regarding the competitive markets of electricity administered by the Market Operator of Electricity and Gas in Romania (OPCOM) - the Intra-Day Market (IDM / IP), the Day Ahead Market (DAM / PZU), the Centralized Market with double continuous negotiation for Electricity Bilateral Contracts(CM-OTC / PC-OTC), the Centralized Market for Electricity Bilateral ContractsExtended Auctions Mechanism (CMBC-EA / PCCB-LE) and the Centralized Market for Electricity - Bilateral Contracts-Continuous Negotiation Mechanism (CMBC-CN / PCCB-NC). 
Table 1. Some basic indicators of the electricity markets are centralized or managed by OPCOM, January 2016 - August 2018

\begin{tabular}{|c|c|c|c|}
\hline & Quantity traded (MWh) & $\begin{array}{c}\text { Percentage of net } \\
\text { predicted } \\
\text { consumption }\end{array}$ & $\begin{array}{l}\text { Weighted average } \\
\text { price (lei / MWh) }\end{array}$ \\
\hline & \multicolumn{3}{|c|}{2016} \\
\hline IDM & 131.329 & $0,2 \%$ & 126,12 \\
\hline DAM & 25.809 .568 & $47 \%$ & 154 \\
\hline CM-OTC & 39.954 .562 & $72,8 \%$ & 156,24 \\
\hline CMBC-EA & 16.817 .235 & $30,6 \%$ & 156,54 \\
\hline CMBC-CN & 15.628 .602 & $28,5 \%$ & 156,01 \\
\hline \multirow[t]{2}{*}{ Total OPCOM } & 98.341 .296 & $179,1 \%$ & 155,63 \\
\hline & \multicolumn{3}{|c|}{2017} \\
\hline IDM & 152.440 & $0,3 \%$ & 178,85 \\
\hline DAM & 24.715 .882 & $43,5 \%$ & 227,69 \\
\hline CM-OTC & 26.117 .215 & $45,9 \%$ & 195,26 \\
\hline CMBC-EA & 43.462 .303 & $76,4 \%$ & 176,06 \\
\hline CMBC-CN & 21.828 .431 & $38,4 \%$ & 197,34 \\
\hline \multirow[t]{2}{*}{ Total OPCOM } & 116.276 .271 & $204,4 \%$ & 195,35 \\
\hline & \multicolumn{3}{|c|}{ First 8 months of 2018} \\
\hline IDM & 128.213 & $0,3 \%$ & 97,37 \\
\hline DAM & 15.351 .005 & $40,8 \%$ & 185,98 \\
\hline CM-OTC & 24.449 .733 & $65 \%$ & 206,64 \\
\hline CMBC-EA & 15.078 .754 & $40,1 \%$ & 218,42 \\
\hline CMBC-CN & 12.862 .204 & $34,2 \%$ & 214,96 \\
\hline Total OPCOM & 67.869 .908 & $180,5 \%$ & 205,95 \\
\hline
\end{tabular}

Source: Author's own processing of data published by OPCOM

It could be noted how the amount of electricity traded on OPCOM platforms grew by over 18\% in 2017 compared to the same period of the previous year, given that the expected net consumption grew for about 3.6\%. Since a significant portion of electricity transactions took place between resellers, this development made the total quantities marketed on the OPCOM platforms to exceed by more than $100 \%$ the net consumption forecast in 2017 , having exceeded consumption by $80 \%$ in 2016. In the first eight months of 2018, transactions on OPCOM platforms exceeded the estimated net consumption of about $80 \%$, similar to the year 2016, with the indication that the share of futures markets is higher 2018 than in 2016.

The central market is administrated by OPCOM. We may observe significant varieties both from year to year and from one market to another. Thus, the quantity traded on PCCBLE and the market share of this market increased significantly in 2017, then drastically declined in the first 8 months of 2018, while the PC-OTC trend appears to be diametrically opposed (a significant decrease in 2017 and return to the first 8 months of 2018). It is also noted that the annual increase in the forecasted net consumption of DAM is gradually decreasing in the analyzed period, from $47 \%$ in 2016 to around $41 \%$ in the first 8 months of 2018, which may suggest a slight change in the behavior of the market participants, respectively the inclination to term contracting, to the detriment of the short term. The electricity quantities traded on IP and authorities weighted their consumption of this market remain very low in the analyzed period. 
The prices recorded on the centralized markets also recorded significant developments between January 2016 and August 2018. Thus, the weighted average price of DAM increases strongly in 2017 to around 228 lei / MWh (from 154 lei / MWh in 2016), after which were significantly reduced in 2018, and reaching about 186 lei / MWh. On the other hand, average prices on the futures markets (PC-OTC, PCCB-LE and PCCB-NC) increase both in 2017 and in 2018. It curls prices in the period under review is simultaneously influenced by many factors, both behavioral (i.e. change certain ways of transacting appetite) and structural (i.e. increased consumption due to a relatively stagnant production, combined with changes in the production structure).

To present the full picture of the evolution of electricity prices in Romania, we marked below the average monthly prices on each centralized market managed by OPCOM (ignoring PI, given its very low share).

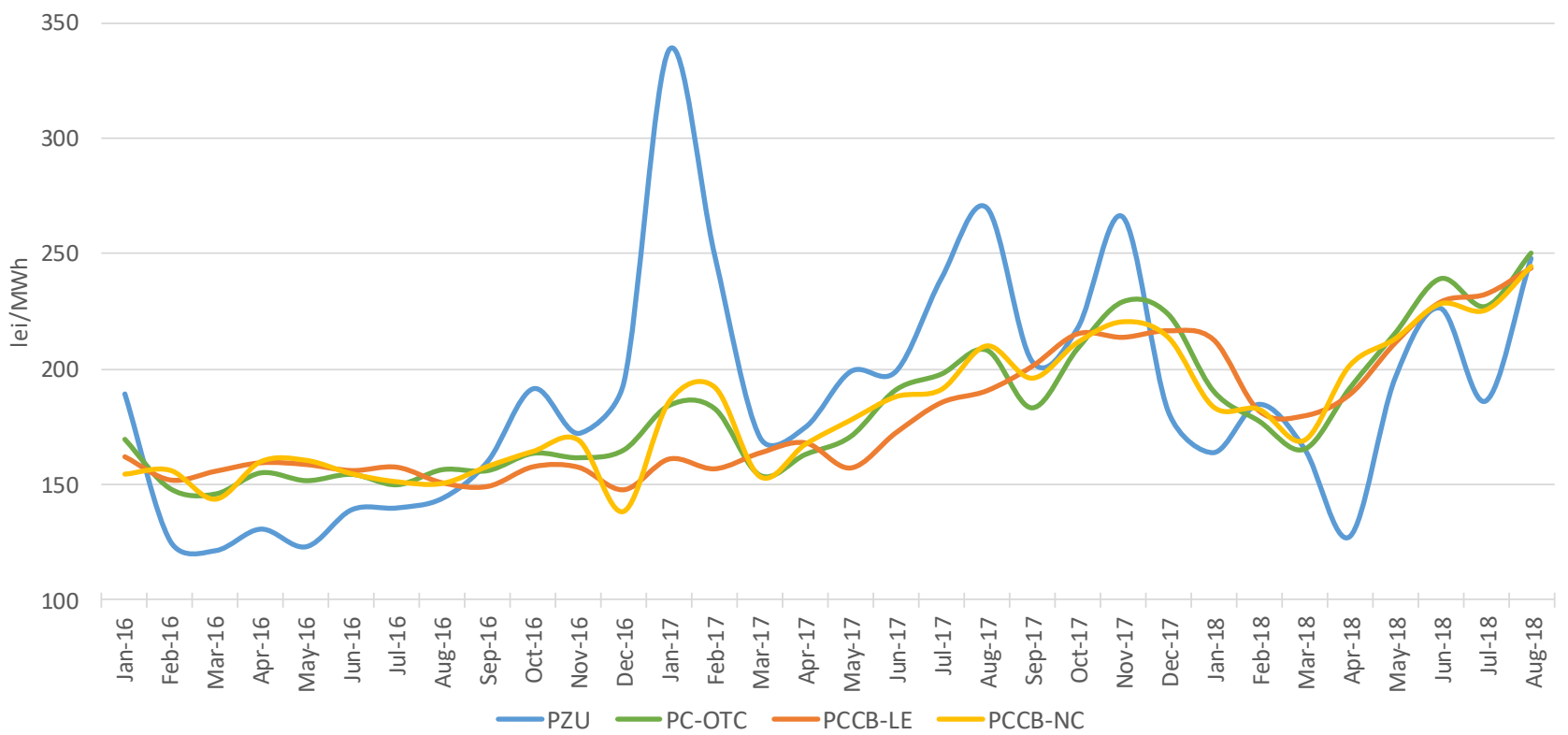

Figure 3. Monthly evolution of weighted average prices on competitive markets managed by OPCOM, January 2016 - August 2018

Source: Data published by OPCOM

The graph above shows the volatility of the DAM (general characteristic of spot markets), and the upward trend in prices of futures markets recorded especially during 2017. Year 2018 is characterized by significant fluctuations both in terms of price PZU and prices futures markets are or tend to reduce their average prices in the first four months of the year is being reversed in the remainder.

The regional context is another important element in the formation of the price of electricity interconnections between different countries leading to cross-border transactions that result in an approximation of electricity prices. In this context, it should be stressed that Romania joined the 4M Market Coupling project (4MMC) with Hungary, the Czech Republic and Slovakia as of the end of 2014, a project involving the price coupling of the next day markets in the four countries. The following graph illustrates the evolution of the spot market 
prices in the region, besides the 4MMC countries, and the prices in Bulgaria, Serbia and Greece.

The graph shows the relatively similar evolution of spot market prices in the region over the period under review, which may indicate that certain weather conditions are similar in several countries (for example, hydraulic, cold or heat waves, etc.) The weather may be different, particularly in smaller areas (i.e. wind power). The differences in prices recorded in the region, especially in terms of their level, are probably related to the structure of the production sources in each country, to the impact of specific regulations, but also to the level of interconnection with neighboring countries.

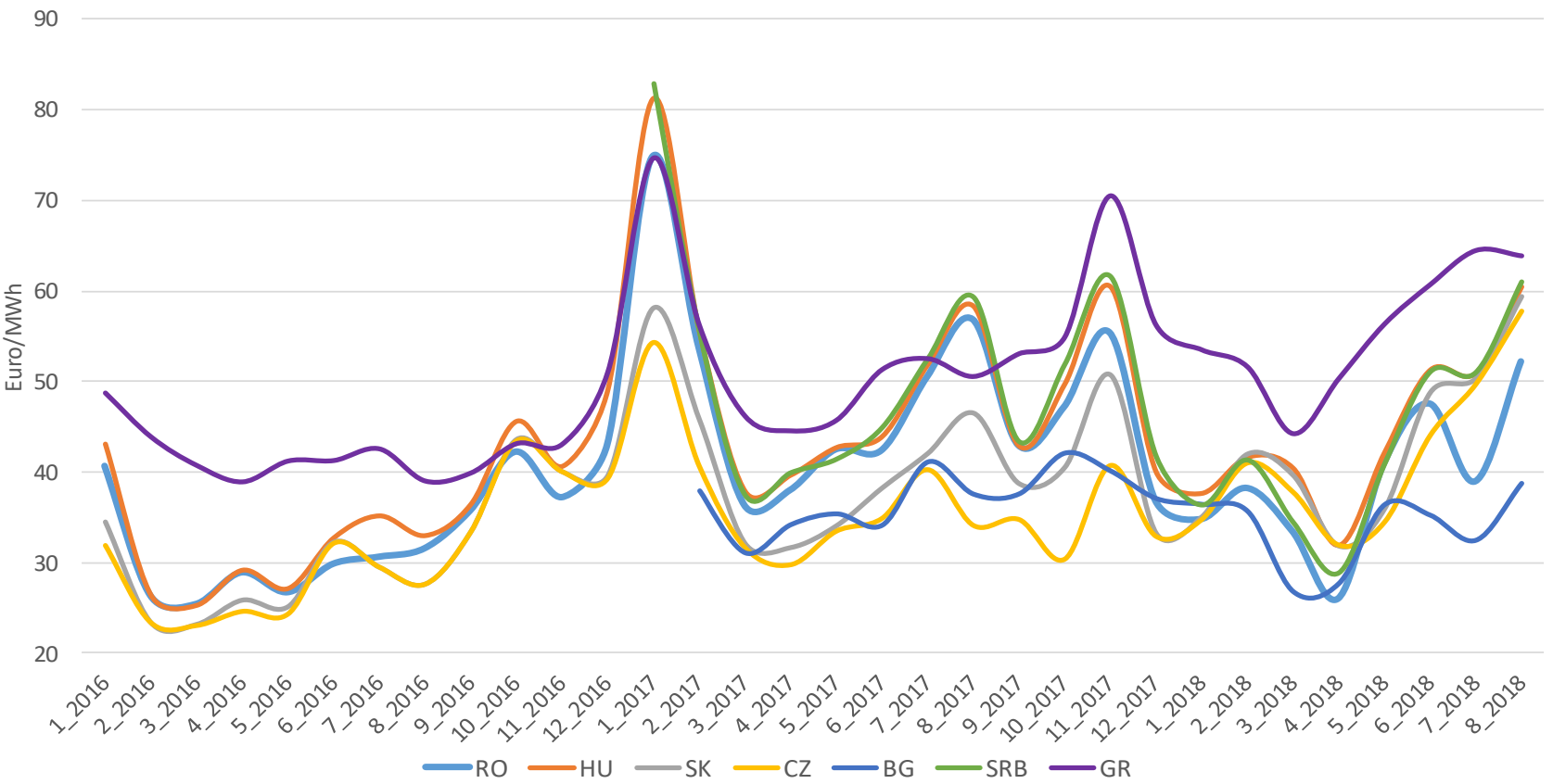

Figure 4. Monthly evolution of spot market prices in the region, January 2016 - August 2018 Source: Data published by OPCOM and ENTSO-E

Thus, the very close trend of spot prices in Romania and Hungary (starting in 2017 and those in Serbia) is observed. Slovakia and the Czech Republic is another pair of states that seem to move in tandem in terms of spot prices of electricity, while Bulgaria and Greece show only relatively similar developments at different levels.

To check the similarity of price movements electricity spot markets in the region, linear correlation coefficients of the monthly price were calculated for each pair of countries that presented in Figure 4. The matrix of linear correlation coefficients is presented below (in the case of Bulgaria and Serbia, the interpretation of the coefficients should take into account the fact that the data series are lower).

Table 2. The matrix of the coefficients that linearly correlate spot market prices in the region

\begin{tabular}{|l|c|c|c|c|c|c|c|}
\hline & RO & HU & SK & CZ & BG & SRB & GR \\
\hline RO & 1 & $97.4 \%$ & $85.1 \%$ & $71.3 \%$ & $75.4 \%$ & $96.9 \%$ & $76.8 \%$ \\
\hline HU & & 1 & $92.4 \%$ & $81.8 \%$ & $62.4 \%$ & $99.2 \%$ & $83.2 \%$ \\
\hline
\end{tabular}




\begin{tabular}{|l|l|l|c|c|c|c|c|}
\hline SK & & & 1 & $94 \%$ & $37.9 \%$ & $86.1 \%$ & $81.8 \%$ \\
\hline CZ & & & & 1 & $14.4 \%$ & $68.7 \%$ & $74 \%$ \\
\hline BG & & & & & 1 & $71 \%$ & $46.5 \%$ \\
\hline SRB & & & & & 1 & $78.7 \%$ \\
\hline GR & & & & & & & 1 \\
\hline
\end{tabular}

Source: Authors' own calculations based on data published by OPCOM and ENTSO-E, from January 2016 to August 2018

The figure below shows the values of the correlation coefficients for the markets coupled with the 4MMC project, but also the other values related to Romania (in relation to Bulgaria, Serbia and Greece). With Table 1, this f course, the whole show that, in general, spot market prices are highly correlated between the neighboring countries, including interconnections are probably stronger.

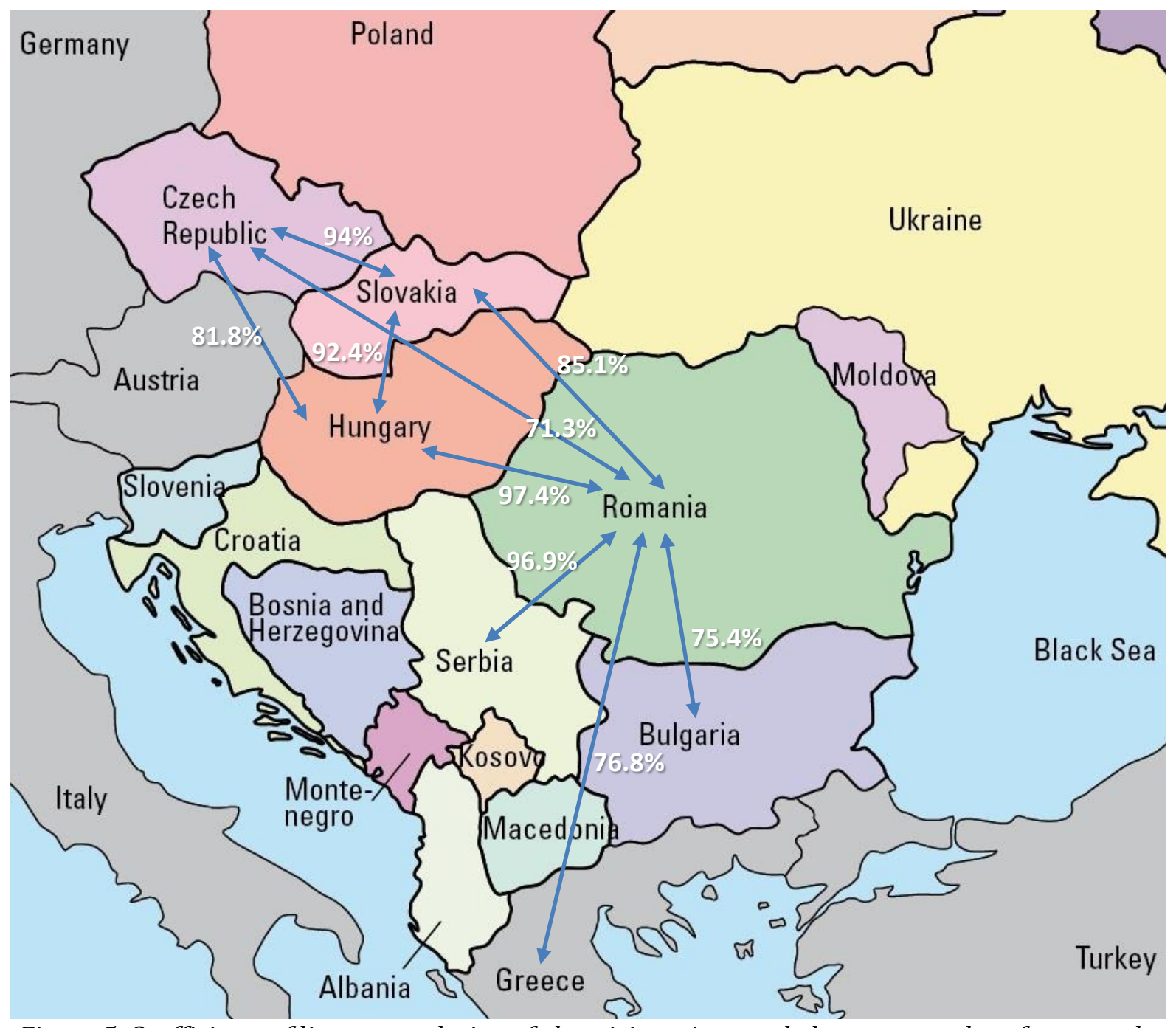

Figure 5. Coefficients of linear correlation of electricity prices traded on spot markets for several pairs of countries in the region

Source: Authors' own calculations based on data published by OPCOM 


\section{Conclusion}

Looking at the last published draft of Romania's Energy Strategy (Romanian Ministry for Energy, 2018), it reiterates the importance of interconnections in Central and Eastern Europe. These are not only supposed to contribute to the development of energy markets but also to the regional energy security mechanisms that will operate under common EU rules.

Concluding, based on the performed study, between January 2016 and August 2018, the electricity markets experienced important evolutions in Romania, both in terms of size and prices, developments based on both structural and behavioral factors. Regarding the prices of the spot markets, they seem to perform relative similar evolutions in the period under review in several countries in the region, while the correlation of prices seemed to be stronger when the level of interconnection of electricity is higher.

We can also conclude that spot market prices had relatively similar developments over the period analyzed in several countries in the region, with price correlations seeming to be even stronger as the interconnection of electricity grids is higher.

Moreover, the results confirm the economic theory, namely that increasing the interconnection of electricity markets can lead to energy prices being brought closer, but also to mitigating the shocks that are affecting these markets. Therefore, as economic theory suggests, increased interconnection of electricity markets can lead not only to convergence in energy prices, but also to alleviate shocks manifested in these markets.

Looking at Romania's strategic plans, the interconnection of Romania's electricity transmission system with the Republic of Moldova's system should be studied in subsequent research attempts. Similar to the approach of Lago et al. (2018,) further research should also explore different methods to incorporate market integration in electricity price forecasting and to improve the predictive performance.

Andrei (2015) underlines the necessity for Romania to take adequate political, legislative and administrative measures to reduce the pressure on the final energy consumer (whether domestic or non-domestic) and to decrease the number of vulnerable consumers. These measures can only be achieved through a smart market design, which definitely asks for further research.

Some possible limits of the study are evidenced by Kobans's 2017 published article. The study proposes a different approach for investigating the impact of market coupling on electricity prices in the Hungarian and Romanian markets by employing the Markov regimeswitching model with time-varying transition probabilities. Kobans' study shows that the persistence and occurrences of Hungarian price drops are significantly increased. Meanwhile, Romanian prices exhibit less and shorter living price jumps. Considering timevarying transition probabilities as functions of wind power production in Romania, the study also reveals that market coupling changed the influence of wind power production on the regime-switching mechanism of electricity prices (Koban, 2017).

\section{References}

Andrei, A.C. (2015). The Liberalization of the Electricity and Gas Markets - Top Priority for Romania's Energy Security. Proceedings Of BASIQ 2015 International Conference: New Trends in Sustainable Business and Consumption, 139-146. 
Bianco, V., Manca, O., Nardini, S., \& Minea, A. A. (2014). An analysis of the electricity sector in Romania. Energy Sources, Part B: Economics, Planning, and Policy, 9(2), 149-155.

Bianco, V., Manca, O., Nardini, S., \& Minea, A. A. (2010). Analysis and forecasting of nonresidential electricity consumption in Romania. Applied Energy, 87(11), 35843590.

Cîrstea, S., Martiş, C., Cirstea, A., Constantinescu-Dobra, A., \& Fülöp, M. (2018). Current Situation and Future Perspectives of the Romanian Renewable Energy. Energies, 11(12), 3289.

Cristea, A.S. (2013). Multi-Criteria Analysis of the Electricity Market in Romania. Proceedings of 12th International Conference on Informatics in Economy (IE 2013), Education, Research \& Business Technologies, 496-500.

Diaconu, O., Oprescu, G., \& Pittman, R. (2009). Electricity reform in Romania. Utilities Policy, $17(1), 114-124$.

European Network of Transmission System Operators (2019). www.entsoe.eu.

Karova, R (2011). Regional electricity markets in Europe: Focus on the Energy Community. Utilities Policy, 19(2), 80-86, DOI: 10.1016/j.jup.2010.10.001

Kennedy, D. (2005). South-East Europe Regional Energy Market: challenges and for Romania. Energy Policy, 33(17), 2202-2215, DOI: 10.1016/j.enpol.2004.04.018

Koban, V. (2017). The impact of market coupling on Hungarian and Romanian electricity markets: Evidence from the regime-switching model. Energy \& Environment, 28(5-6), 621-638, DOI: $10.1177 / 0958305 X 17714152$

Lago, J., De Ridder, F., Vrancx, P. \& De Schutter, B. (2018). Forecasting day-ahead electricity prices in Europe: The importance of considering market integration. Applied Energy, 211, 890-903, DOI: 10.1016/j.apenergy.2017.11.098

Majstrovic, G., Tot, M. \& Medic, I. (2006). An analysis of the South East Europe electricity market, Proceedings of the 6th IASTED International Conference on European Power and Energy Systems, 256.

Majstrovic, G., Bajs, D. \& Sutlovic, E. (2008). Correlation and Regression of Wholesale Electricity Market Daily Prices in Europe. International Review of Electrical Engineering-IREE, 3(4), 699-708.

Moraru, D. \& Hristescu, C. (2016). Electricity Market Auction Settings - A Comparison between Marginal Pricing System (MPS) and Pay-as-Bid (PAB) for the Romanian Market. Proceedings of the 10th International Conference on Business Excellence, 3545.

Malla, S., \& Timilsina, G. R. (2019). Assessment of long-term sustainable end-use energy demand in Romania. International Journal of Sustainable Energy, 38(3), 253-275.

Marić, R., \& Vukmirović, G. (2018). Sustainability in International Food Retailing: The Case Of Western Balkans. Trade Perspectives, 59.

Paun, D. \& Paun, C.A. (2017). The Impact of Renewable Energy on the Price of Energy in Romania. International Journal of Renewable Energy Research, 7(2), 540-546.

Romanian Gas and Electricity Market Operator OPCOM (2019). www.opcom.ro.

Romanian Ministry for Energy (2018). Strategia energetică a României 2019-2030, cu perspectiva anului 2050. Retrieved from http://energie.gov.ro/transparentadecizionala/strategia-energetica-a-romaniei-2019-2030-cu-perspectiva-anului$2050 /$. 
The European Parliament and The Council Of The European Union (2018). Directive (EU) 2018/2001 of the European Parliament and of the Council of 11 December 2018 on the promotion of the use of energy from renewable sources. Retrieved from https://eur-lex.europa.eu/legalcontent/EN/TXT/?uri=uriserv:OJ.L_.2018.328.01.0082.01.ENG.

Verbič, M., Filipović, S., \& Radovanović, M. (2017). Electricity prices and energy intensity in Europe. Utilities Policy, 47, 58-68.

Zachmann, G (2008). Electricity wholesale market prices in Europe: Convergence? Energy Economics, 30 (4), 1659-1671, DOI: 10.1016/j.eneco.2007.07.002. 